\section{Planning for the old and very old}

The next 30 years will see a continuing increase in the proportion of old people in the population, and in particular in the numbers of the very old. Though over $95 \%$ of old people live at home (and will presumably continue to do so), institutional care of some kind is necessary for the remainder. At present this is shared among the hospital service, local authority old people's homes, and (to a small extent) voluntary and private nursing and other homes. The practical problems faced by planners looking ahead have been made plain by current studies of levels of disability and needs for care. The most recent ${ }^{1}$ was of over 4500 old people in institutional care in Leicestershire, where there were 105000 people over 65 . The proportion of old people in care was only $2 \%$ in the 65-74 age group but this rose to nearly half among those over 95. Roughly, the ratio doubled with every six years of age. Something like half of those in care were in local authority old people's homes, over $80 \%$ of these being over 75 years of age. One-third were in geriatric or psychiatric hospitals, about equally distributed between the two; those in psychiatric care were younger than those in geriatric. The remaining $16 \%$ were in acute hospitals or private care.

The old people in local authority homes showed substantial disability. Only $38 \%$ had unimpaired mobility, and $24 \%$ were at least occasionally incontinent. Unfortunately, no figures were given for the proportion who were confused or demented. Those in hospital had considerably more disability, but since so many more were in homes calculations show that about half of the total of incontinent old people in institutional care were in local authority homes. Overall, the general pattern was very similar to that found elsewhere ${ }^{2} 3$-but a point worth emphasis is that in any one home the problems can never be static, because physical and mental disabilities increase as the residents inevitably age, and this imposes further burdens on staff. ${ }^{4}$

The changing demographic pattern of old age suggests, however, that the load may be lightened in some ways in the coming years. By the end of the century many more old people will have been married, and a higher proportion of them will have had children. ${ }^{5}$ This may lessen the pressure on institutional care, since people who have never married are considerably more likely to require such care than those who have. Another cheering fact is that many elderly people at present in local authority homes are suitable for care in sheltered housing, in which their independence and dignity can be better maintained at considerably lower cost. An enlightened housing policy which encouraged children to move near their elderly parents or parents near their children would do much to mitigate the ill effects of the dispersal of families that has characterised the past 30 years. Special accommodation of hostel type is also needed for old people with mental disorder, since their care in the community may impose intolerable burdens on families.

Perhaps the most important immediate problem is for the criteria for admission to local authority homes to be more clearly defined and more uniformly applied than is at present the case. Another important gap in the system is that accurate medical assessment should be routine before admission, since a substantial number of those admitted to old people's homes are likely to benefit from hospital treatment, perhaps on a day hospital basis, and might well be able to remain at home as a result. ${ }^{6}$ Action to reduce delays in transfer from expensive hospital care could reduce costs considerably. The levels of nursing and medical care required for residents in old people's homes need to be examined and agreed, and more attention given to the training of staff. Care of the elderly is a demanding job, and it requires special knowledge of the physical and mental problems of old people.

A recent DHSS circular ${ }^{7}$ suggests ways of improving the care of inpatients, but dramatic solutions to the problems of providing and financing care of the elderly seem unlikely. Nevertheless, with clarity of thought and uniformity of application of well-defined principles substantial improvements are possible without any greater expenditure of resources.

${ }^{1}$ Clarke, M, et al, Health Trends, 1979, 11, 17.
2 Carstairs, V, and Morrison, M, The Elderly in Residential Care. Edinburgh,
Scottish Home and Health Department, 1972 .
3 Townsend, P, in Needs of the Elderly for Health and Welfare Services,
ed R W Canvin and N G Pearson. Exeter, University of Exeter, 1973.
4 Wilkin, D, Mashiah, T, and Jolley, D J, British Medical fournal, 1978,
2, 1274.
${ }^{5}$ Robertson, C, Gilmore, A, and Caird, F I, Health Bulletin, 1975, 33, 76.
${ }^{6}$ Lowther, C P, and McLeod, H M, Health Bulletin, 1974, 32, 14.
7 Department of Health and Social Security, A Programme for Improving
Geriatric Care in Hospital, HN(79)35. London, DHSS, 1979.

\section{The national filth}

The squalor found by T D V Swinscow ( $p$ 999) is not confined to Southampton Airport: it may be seen in our roads, public buildings, railway tracks, and beauty spots-as if we in Britain were determined to restore it to a state of filth where an 18th century person such as Defoe's Moll Flanders would feel at home. Despite conferences and national litter weeks, despite laws-flouted daily as anybody can see (but with a derisory number of prosecutions)-the accumulation grows; some parts of our hospitals, new and old, are now little cleaner than the worst of our railway stations. Apologists might blame this filth on a primary shortage of workers, or cuts in their numbers, yet they would be confounded by the evidence of their eyes or the statistics. At some London termini railway passengers are besieged by numerous porters anxious to carry their luggage while the station concourse and platforms remain full of litter and the lavatories remain filthy. The records show a rise in the number of cleaners in general-and in discussing possible financial cuts a point hospital doctors repeatedly made to our special correspondent was the large number of cleaners in our hospitals doing little, with no one in authority enforcing work or standards.

In part this state of affairs reflects the overall disregard of standards and the tendency to vandalism that exist not only in Britain but all over Europe, including the Iron Curtain countries. Yet, as any traveller can see, in the civilised world filth seems to have reached its apogee in this country, and so in seeking immediate and new remedies we need to ask several questions. Do we do enough. for example, to teach schoolchildren about litter? Should they, say, spend one period a month clearing the district surrounding their school ? Should we employ non-violent prisoners and juvenile offenders on continually clearing our derelict land, motorways, and railway tracks? Has any authority considered employing half the number of road sweepers but paying them double their present rates for high standards of work that are rigorously 
enforced? Why has this country smugly rejected the experience of others (which provide numerous and large, non-vandalisable litter bins) and either removed litter bins altogether or installed ludicrously small plastic ones that are overflowing or destroyed by hooligans within a few hours? And, given that much of the problem arises from sweet and cigarette wrappings and metal drink cans, should we not alter our attitudes to packaging: in the second world war we accepted chocolates and tobacco with the minimum of wrapping, and is there not a case for introducing a compulsory swingeing deposit on packaging$10 \mathrm{p}$ for a can or cigarette packet-thereby encouraging people to return them or to collect them for money?

Finally, there remains the rule of law, symbolically as important with litter as with any other of its provisions. Perhaps we shall realise that any government really means business when not only is the inflation rate in line with our competitors, but our drink-driving laws are enforced, football violence is a thing of the past, and our students can walk about a university campus without the fear of rape. When all this occurs it will also be doubtful whether, as happened this year, a Nordic country will be able to show a television programme illustrating the squalid conditions any traveller is likely to encounter at London Airport.

\section{Meningococcal septicaemia}

Fortunately outbreaks of meningococcal disease are uncommon in Britain and a general practitioner is unlikely to see more than one or two cases in a lifetime. Physicians specialising in infectious diseases and paediatricians are, however, aware that meningococcaemia runs a fulminating course and sometimes relentlessly progresses to death, especially in children. A recent report in the $B M \mathcal{F}^{1}$ of 10 deaths in infancy from meningococcal infection highlights this rapidly fatal propensity, and the fact that many family doctors are unaware of the importance of a haemorrhagic rash in a febrile child. Meningococcal infection is a medical emergency, and there is great urgency in starting treatment with antibiotics: there appears to be a stage beyond which this has no effect on the disease, probably owing to the organism's triggering irreversible immunological mechanisms.

Meningococcal septicaemia may start abruptly, especially in children, with fever, vomiting, and sometimes a convulsion. In babies the onset may be insidious, with apathy, anorexia, and irritability. The rash may be seen in from $20 \%$ to $50 \%^{2}$ of cases and may be macular (sometimes with lesions on the face), though typically it is haemorrhagic with petechiae or larger areas of purpura. The petechiae frequently start on the buttocks and the back, which should be examined in all children with undiagnosed febrile illnesses. Whereas meningococcal meningitis is always associated with septicaemia, the reverse does not necessarily occur, and the most fulminating meningococcaemias often present without signs of meningeal irritation, in which case a purpuric rash is especially common.

The antibiotic of choice for meningococcal septicaemia is benzylpenicillin given by intramuscular or intravenous injection. Should a general practitioner suspect the diagnosis he should give the child an injection of penicillin without delay, and then arrange for immediate admission to hospital. Doctors have sometimes been concerned that giving penicillin to a child with suspected meningococcal meningitis might obscure the diagnosis subsequently, but this possibility is unlikely, as now that the cerebrospinal fluid can be examined by countercurrent immunoelectrophoresis the diagnosis can be confirmed immunologically.

In the children described by Oakley and Stanton ${ }^{1}$ there was a mean delay of over an hour between the ambulance being called and the child reaching hospital. A practitioner suspecting meningoccaemia should consider taking the child to hospital in his own car or ensuring that the parents or relatives do so, and hospital admitting officers talking on the telephone to a general practitioner about a child with a haemorrhagic rash should advise him along these lines.

On admission to hospital the child should be given benzylpenicillin every four hours by intravenous bolus injection, reducing to six hourly when clinical response occurs; in children who are allergic to penicillin chloramphenicol is a satisfactory alternative. Intrathecal injection is unnecessary and hazardous. Intravascular coagulation is a common complication of meningococcal septicaemia but we have no evidence that routine treatment with heparin is indicated. The same advice applies to corticosteroids, although most clinicians faced with a near-moribund patient would probably give a large dose of hydrocortisone by intravenous injection.

Finally, the epidemiological aspects of meningococcal infection should not be ignored. The disease is notifiable to the medical officer for environmental health, and close family contacts of the patient should be treated prophylactically with minocycline or rifampicin. Penicillin is not effective for prophylaxis, and sulphonamides should be used only if the organism is known to be sensitive to them, as sulphonamideresistant meningococci are now common in Britain. ${ }^{3}$

\footnotetext{
${ }^{1}$ Oakley, J R, and Stanton, A N, British Medical fournal, 1979, 2, 468.

${ }^{2}$ Christie, A B, Infectious Diseases: Epidemiology and Clinical Practice, 2nd edn. Edinburgh, Churchill Livingstone, 1974.

${ }^{3}$ Fallon, R J, in Recent Advances in Infection, ed D S Reeves and A M Geddes, p 77. Edinburgh, Churchill Livingstone, 1979.
}

\section{Hair-raising treatment}

Why, in biological terms, men become bald remains a mystery, though it may be a suitable subject for an evening's idle discussion; but the impact of the condition on its victims is sufficient to encourage many to seek treatment for the inexorable decline in their half-million terminal scalp hairs. This is, sadly, one condition in which prophylaxis is not the best approach: of the two methods known to be effective, the careful selection of parenteral genes is impossible and early castration is unacceptably drastic.

Yet to the unbiased observer the most puzzling question is why baldness in men needs any treatment. Loss of hair is a visible sign that male hormones have been exerting their influence, so why should a man want to disguise this evidence of his masculinity? Perhaps the key lies in the fact that baldness-like going grey-normally implies advancing years, so that the search for a cure may be no more than a symptom of man's desire for eternal youth. The NHS recognises that this desire is misplaced: it specifically excludes from its subsidised tariff the prescription of wigs for the purpose of concealing male alopecia-though should there be concomitant cicatricial alopecia or alopecia areata an NHS wig becomes available.

For the dermatologist there are two problems to be faced 